\title{
SÉRIES NO ENSINO PRIVADO, CICLOS NO PÚBLICO: UM ESTUDO EM BELO HORIZONTE
}

\author{
PAULO ROBERTO VIDAL DE NEGREIROS \\ Colégio Santo Agostinho - Contagem - MG \\ negreirosp@uol.com.br
}

\begin{abstract}
RESUMO
O objetivo deste estudo é entender o fenômeno que tem ocorrido nas esferas de ensino público e privado no Brasil no que diz respeito à aplicação do art. 23 da Lei de Diretrizes e Bases da Educação Nacional - LDB -, Lei n. 9.394/96, que trata da organização dos tempos escolares. Ao flexibilizar e delegar a autonomia aos estabelecimentos de ensino na escolha da organização dos tempos escolares esta lei acabou provocando uma situação diversificada. Os dados revelam que a rede pública movimenta-se mais rapidamente para uma organização em ciclos enquanto que a rede privada de ensino mostra-se mais propensa à continuidade da organização seriada. Dados estatísticos recentes, fornecidos pelo Instituto Nacional de Estudos e Pesquisas Educacionais Anísio Teixeira - Inep - comprovam isso. As razões pelas quais os estabelecimentos de ensino público adotam o sistema de ciclos têm sido objeto de muitas publicações. No entanto, quando a escola particular é o foco dessa questão, não se sabe ao certo quais as razões da não adesão à proposta dos ciclos e nem os motivos da continuidade do sistema seriado.

EDUCAÇÃO PÚBLICA - ADMINISTRAÇÃO DA EDUCAÇÃO - ENSINO PARTICULAR - BELO HORIZONTE
\end{abstract}

\section{ABSTRACT}

GRADES IN PRIVATE SCHOOLS, LEARNING CYCLES IN PUBLIC SCHOOLS: A STUDY CARRIED OUT IN BELO HORIZONTE. The objective of this study is to understand what has been occurring in the spheres of public and private education in Brazil, concerning the application of art. 23 of the Guidelines and Bases Act of Education - LDB -, Law n. 9.394/96,

Este artigo fundamenta-se na pesquisa de mestrado intitulada "A Seriação enquanto organização dos tempos escolares na rede privada de ensino de Belo Horizonte". A dissertação foi apresentada em julho de 2004 dentro do Programa de Mestrado em Educação da Pontifícia Universidade Católica de Minas Gerais - PUC-MG. 
which deals with the organization of school times. This law has caused a diversified situation by allowing flexibility and delegating autonomy to teaching institutions to decide on school time's organization. The data indicate that the public schools are moving more quickly towards an organization based on cycles, whereas the private ones are more inclined to keep grades. Recent statistic data, supplied by the National Institute of Pedagogical Studies and Research Anísio Teixeira - Inep -, prove it. The reasons why public teaching institutions adopt the learning cycle have been discussed in many publications. However, when the private schools are focused, it is not known what the reasons for non-adhesion to learning cycle are, as well as the motives that make them to maintain the graded system.

PUBLIC EDUCATION - EDUCATIONAL ADMINISTRATION - PRIVATE EDUCATION BELO HORIZONTE

\section{DADOS DE REALIDADE}

Nos últimos anos a temática do tempo escolar tem sido foco de muitas polêmicas no cenário educacional brasileiro. Trata-se de um assunto que tem extrapolado o fórum da academia e ganhado, cada vez mais, espaço e destaque no interior da sociedade. Na maioria das vezes o centro da polêmica está na comparação entre as escolas que passaram a adotar os ciclos de formação e as escolas que continuam com o ensino seriado.

Essa discussão apresenta-se no cotidiano da sociedade nas mais diversas circunstâncias. Em conversas informais entre amigos e familiares, em reuniões de pais e professores, nas discussões pedagógicas, em que os educadores se encontram para discutir possibilidades de avanços qualitativos nas suas práticas, nos pleitos eleitorais, nos congressos, na literatura educacional ou, ainda, na caracterização de escolas públicas e privadas.

Em muitas dessas conversas, as referências a essas modalidades de organização estão impregnadas de muitas conveniências e de um certo senso comum que não abarcam a totalidade das propostas. No contexto da Grande Belo Horizonte, falar em ciclo implica referências quase sempre à "promoção automática" e ao ensino de "qualidade duvidosa". As referências ao ensino seriado, por sua vez estão carregadas de expressões, tais como: ensino apertado, exigente, dá prova, aprova, reprova, passa no vestibular, ensino de "qualidade". O fato é que no calor das discussões a defesa de uma proposta quase sempre ocorre em razão da negação da outra. Uma tendência de polarização com riscos e possibilidades de equívocos conceituais e posições corporativistas.

A conjugação desses diversos cenários provoca em muitos profissionais momentos de incertezas, angústias, debates e estudos. Como conciliar uma 
Séries no ensino privado...

proposta de educação que respeite as diferenças individuais dos alunos e thes assegure o direito à educação, dando-Ihes uma formação humana e solidária, em uma sociedade que, segundo Assman, "vive em meio a um acirramento competitivo, planetariamente globalizado?" Para o autor,

Juntar as duas tarefas - habilitação competente e formação solidária - ficou sumamente difícil, porque a maioria das expectativas do meio circundante (mercado competitivo) se volta exclusivamente para a demanda da eficiência (capacidade competitiva). (| 998, p.61)

Essa parece ser a grande questão que problematiza a ação do educador comprometido com uma educação cidadã. Assumir o desafio de uma prática pedagógica que, inserida numa dada realidade, tenha propósitos coerentes com sua dimensão axiológica, em que as práticas cotidianas estejam impregnadas das relações valorativas. Posicionar-se de forma assertiva em relação à função social da escola que, segundo Arroyo ( 1996), deve ser um espaço de formação, de direito aos saberes e de inserção no processo civilizatório.

Por isso, no atual contexto da educação brasileira, a problemática dos tempos escolares apresenta-se como um assunto desafiador e provocante. Algo que não envolve apenas rotinas do cotidiano escolar, mas que aborda essencialmente uma concepção de educação com implicações sérias para o processo educacional, visto que o olhar pedagógico delimita as práticas educativas. Trata-se de uma decisão que pode envolver políticas de educação com reflexos diretos na vida escolar do aluno e na sua trajetória profissional. Enfim, trata-se de uma opção educativa mais coerente com o projeto de sociedade que se deseja construir: democrática e cidadã.

\section{CONTEXTO HISTÓRICO}

A história do sistema educacional brasileiro revela que, durante o século $X X$, o modelo de organização dos tempos escolares predominante foi a seriação. Existem muitos estudos que identificam sua origem no próprio processo de configuração do sistema escolar, cujas raízes no Brasil remontam às reformas educacionais do final do século XIX, quando da implantação dos grupos escolares. 
Para Saviani (2000), essa prática de ensino surge com a constituição dos sistemas nacionais de ensino na França em meados do século XIX, em que a escola tinha o papel de difundir a instrução e transmitir os conhecimentos acumulados e sistematizados logicamente. Esse modelo estava assentado na pedagogia tradicional que priorizava o intelecto na essência do conhecimento. $\bigcirc$ instrumento principal de trabalho era o professor, e cabia às escolas encontrar profissionais razoavelmente bem preparados. Os grupos escolares caracterizavam-se pelo sistema de classes, em que cada professor dava suas lições, aplicava os exercícios e avaliava o desempenho escolar dos alunos.

Pesquisas realizadas ao longo do século $X X$ mostram que o fracasso desse modelo (pedagogia tradicional) ocorreu pelo fato de a escola não conseguir seu intento de universalização do ensino e porque nem todos os alunos bem-sucedidos ajustavam-se ao modelo de sociedade que se desejava consolidar. Segundo estudos de Patto (1993), a reprovação e a evasão na escola pública ao longo do século assumiram proporções inaceitáveis. Para a autora, a situação revela-se ainda mais grave se considerarmos a antigüidade do problema. Estatísticas publicadas na década de 30 já evidenciavam não só os altos índices de evasão e reprovação mas também o então primeiro ano do curso primário como um ponto crítico da organização do sistema educacional.'

De acordo com Barretto e Mitrulis (200I), estudos comparativos em relação a outros países da América Latina, realizados em meados do século $X X$, mostravam que $57,4 \%$ dos alunos eram retidos na passagem da $1^{a}$ para a $2^{a}$ série do ensino fundamental. Segundo as autoras, dados de 1954 mostravam que as perdas ocasionadas pelas recorrentes repetências e pela evasão escolar atingiam índices consideráveis no país: de cada 100 crianças matriculadas na $I^{a}$ série, apenas 16 concluíam as quatro séries do ensino primário no período previsto. Esse quadro manteve-se ao longo de quase todo o século. Estudando os ciclos e a progressão escolar no Brasil, as autoras afirmam ainda que a reação a essa lógica de exclusão não é recente. Muitas vozes e movimentos levantaram-se para anunciar e denunciar o problema da evasão e da repetência na educação brasileira. No entanto, foi a partir da última década do século $X X$ que o movimento de reorganização dos tempos escolares ganhou

I. O serviço de Estatística Educacional da Secretaria Geral de Educação registrava 53,52\% de retidos no $1^{\circ}$ ano em 1936 (Cardoso, apud Patto, 1993). 
Séries no ensino privado...

contornos mais expressivos. Muitas cidades brasileiras, tais como Rio de Janeiro, São Paulo, Porto Alegre, Belém e Belo Horizonte, implantaram reformas substanciais na reorganização dos tempos escolares em suas redes de ensino.

\section{ORGANIZAÇÃO DOS TEMPOS ESCOLARES NA LDB N. 9.394/96}

Embora já fosse admitido a título de experiência pedagógica durante os anos 60 e estivesse previsto na Lei n. 5.692/71, o regime de ciclos ganhou de fato grande impulso na década de 90 a partir da nova Lei de Diretrizes e Bases da Educação Nacional n. 9.394/96 que, ao "flexibilizar, descentralizar e desregulamentar" (Cury et al., 1997), abriu caminhos para as escolas recriarem ou inovarem seus modelos de organização pedagógica.

Ao que tudo indica, a abertura permitida por essa lei acabou gerando um fenômeno curioso pelo qual a rede pública movimenta-se mais fortemente para uma organização em ciclos enquanto a rede privada manifesta um processo bem mais lento, sustentando-se basicamente na seriação. Dados de 2003, fornecidos pelo Inep, referentes ao cadastro escolar nacional sobre o número de escolas segundo a forma de organização, comprovam esse fenômeno. Em relação ao Brasil, o quadro apresenta-se da seguinte maneira: 81, I \% dos estabelecimentos de ensino adotam o sistema seriado, I I \%, o regime de ciclos e 7,9\% adotam mais de uma forma de organização. Na esfera estadual, 57,6\%, o seriado, 26, 1\%, o de ciclos e 16,3\%, mais de uma forma; nas redes municipais, $84,9 \%$, o seriado, $8,3 \%$, o de ciclos e $6,7 \%$, mais de uma forma; em relação às escolas particulares os números evidenciam que $96,5 \%$ continuam com a seriação, 2\%, adotam ciclos e I,4\%, mais de uma organização. Essa mesma análise comparativa para o Estado de Minas Gerais revela que 60,4\% dos estabelecimentos escolares adotam o sistema seriado, 36,2\%, o de ciclos e 3,4, mais de uma forma de organização. Na esfera da rede estadual de ensino $31,3 \%$, o seriado, 65,2\%, o de ciclos e 3,6\%, mais de uma forma; nas redes municipais $67,3 \%$, o seriado, $28,9 \%$, o de ciclos e 3,8\%, mais de uma forma; na iniciativa privada há $98 \%$ das escolas com sistema seriado, 1,9\% com ciclos e 0,1\% com mais de uma forma de organização.

Do ponto de vista legal, pode-se afirmar que a flexibilização que a LDB assegura quanto à organização dos tempos escolares implica, em tese, que em qualquer uma das alternativas apresentadas está implícita uma proposta de educação coerente com os princípios legais. Assim, considera-se não haver nada 
de anormal ou ilegal na adoção de qualquer uma dessas alternativas de organização dos tempos escolares.

\section{O OBJETO DA PESQUISA}

que chama a atenção quanto a tendências manifestas entre a rede pública (ciclo) e a rede privada (seriação) é a sustentação das respectivas opções. Na rede pública têm sido realizados, de modo geral, muitos congressos, seminários, fóruns, publicações, envolvendo os educadores, um debate sem precedentes visando à explicitação consistente desse modelo de organização escolar, ajustado à função social de uma escola cidadã - a escola de direitos. Na rede privada, por sua vez, a situação é, no mínimo, provocante. Para a elaboração de seus projetos políticos pedagógicos, os colégios fazem contratos isolados com empresas de assessoria pedagógica. Não se conhecem as razões da "resistência" à proposta dos ciclos entendida pelos teóricos como "pedagogicamente correta". Não se sabe até que ponto a questão é ou não analisada, se a temática é discutida como proposta de ação pedagógica que pode contribuir para uma prática mais coerente com os princípios e valores de formação desejados pelos colégios. $\bigcirc$ fato é que existe uma opção predominante pelo ensino seriado, quase que exclusiva. Sabe-se, também, que, normalmente, os registros de alterações implementados ficam restritos ao regimento dos colégios e pouco se conhecem os porquês. Instigado por essa questão, investiguei os motivos da sustentação das séries na rede privada de ensino.

\section{METODOLOGIA}

Sabe-se que a responsabilidade pela gestão das escolas particulares está centrada em um corpo reduzido de pessoas. Normalmente são os proprietários e alguns poucos profissionais da equipe pedagógica que exercem alguns cargos de confiança. Para efeito da pesquisa, a direção de cada colégio indicou uma pessoa com autoridade pedagógica que pudesse falar em nome da escola. Foram essas pessoas (gestores pedagógicos) que se apresentaram preparadas e politicamente constituídas para responderem às questões.

Todas as entrevistas foram gravadas e transcritas. Tal estratégia possibilitou a organização e o estudo dos dados coletados, tendo como referência as 
Séries no ensino privado...

categorias de análise definidas. Como recurso metodológico utilizou-se uma abordagem qualitativa, tendo como suporte um questionário semi-estruturado.

Considerando que o campo da pesquisa, colégios da rede privada de Belo Horizonte, apresenta realidades geográficas, econômicas, sociais ou culturais muito diferentes, delimitou-se a investigação às chamadas grandes escolas: três laicas e três religiosas. São escolas reconhecidas pela sociedade como detentoras de um padrão de ensino de "qualidade". Além disso, não representam unidades isoladas, fazem parte de um conjunto de escolas pertencentes a uma congregação religiosa ou a uma empresa que organiza uma rede de ensino.

Seguem-se as categorias de análise utilizadas na pesquisa.

\section{A concepção de ciclos}

Os gestores pedagógicos dos colégios demonstram conhecer razoavelmente bem a concepção pedagógica dos ciclos de formação. Identificam que nessa concepção o aluno deve ser visto como principal personagem do processo educativo e que, como sujeito da aprendizagem, possui características próprias as quais precisam ser respeitadas. Alguns aprendem mais rápido, outros são mais lentos e o ritmo do ensino precisa ser ajustado ao processo de aprendizagem de cada um. No entanto, em algumas entrevistas a concepção de ciclos está relacionada a uma determinada função social. Trata-se de uma estruturação escolar destinada a certo segmento social com o objetivo de "segurar" o aluno na escola.

Na população carente, mais pobre, rural, o pessoal que ficava, que desistia da escola porque repetia... isso é muito bom, ao invés dele repetir a I a série três, quatro vezes, a gente consegue que ele fique cinco, seis anos na escola, ele vai

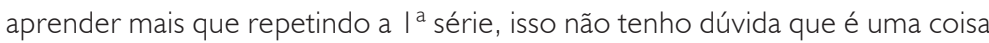
boa.(...) Pra população carente, e dependendo da escola que ele freqüente e a seriedade que o professor encara, isso trouxe muita vantagem, mas pra população que a gente atende aqui, classe média, classe média alta, não seria uma coisa boa.

Essa situação aparece quando os entrevistados sinalizam uma contradição entre a teoria e a prática dos ciclos. Consideram que, do ponto de vista da qualidade do ensino, essa proposta de organização ainda não se mostrou 
confiável, ou seja, não correspondeu às expectativas criadas. Assim, estabelecem uma relação direta dos ciclos com aprovação automática e com alunos pobres. Consideram, no entanto, que do ponto de vista social a proposta apresenta bons resultados, visto que o aluno fica mais tempo na escola. Nesse caso, não seria uma proposta capaz de atender às escolas particulares, das quais se exige a qualidade do ensino oferecido.

\section{Aprovação e reprovação nos colégios}

Se a estrutura seriada foi apontada durante muito tempo como uma organização escolar excludente em razão dos altos índices de reprovação e evasão, torna-se importante saber como andam esses índices na atual conjuntura da escola particular. Saber se a temática da reprovação continua caracterizando o ensino seriado como uma organização escolar excludente ou se apresenta novos contornos. Por isso, nas entrevistas, as perguntas sobre a reprovação tinham como meta levantar dados referentes aos índices de sucesso e fracasso dos alunos nos colégios estudados.

A temática da reprovação foi abordada de forma variada; no entanto, existem dois eixos que garantem certa unidade nas diversas falas: trata-se da concepção de avaliação que os colégios adotam e o conjunto de estratégias implementadas para ajudar os alunos com dificuldades na aprendizagem. A combinação desses elementos interfere positivamente no resultado final, permitindo aos colégios continuarem com os sistemas de provas como principais instrumentos de avaliação e ao mesmo tempo garantirem excelentes resultados nos índices de aprovação. A única exceção vale para o ensino médio. Em alguns colégios, as reprovações aumentam um pouco durante o ensino médio, no entanto, sem evidências de que seja algo preocupante. Em relação ao ensino fundamental, as entrevistas revelam como "muito baixo" ou "baixíssimo" o índice de reprovação.

No que se refere aos processos de avaliação, os dados colhidos nas entrevistas indicam o sistema de provas como um dos elementos calibradores da imagem dos colégios. A impressão é que existe uma política cuidadosa por parte dos gestores das escolas particulares no que se refere às mudanças a serem implementadas; os riscos são dimensionados de forma a não provocar efeitos indesejados na comunidade escolar. Nesse caso, evita-se uma ruptura com a cultura da prova que ainda é muito forte na sociedade. A visão segundo a qual 
Séries no ensino privado...

na sociedade, a todo o momento, os sujeitos são avaliados e seu desempenho tem implicações econômicas, sociais e culturais acaba sendo um elemento forte para a justificativa da manutenção dos sistemas de provas como principais instrumentos de avaliação. A família quer exigência e qualidade, mas não aceita o fracasso em relação aos seus filhos. Essa situação é tolerada para outros alunos e, quando ocorre, isso parece refletir que se trata de uma escola séria.

A maioria dos pais entende isso. Quando o aluno não acompanha, não está tendo um bom resultado ou não tem maturidade pra ir pra série seguinte, isso é analisado no conselho de classe, não é pura e simplesmente uma nota, a gente mantém a cobrança de prova sim, e é um dos estímulos para que o aluno estude. A gente acredita nisso, nesse tipo de avaliação e o que define se o aluno vai repetir ou não é a análise do conselho de classe, que acompanha esse aluno bem mais de perto. Então é isso, é trabalhado com o aluno e com a família o ano inteiro... a maioria aceita, alguns pais, eu tenho problema... os pais hoje, alguns pais não querem colocar os filhos na escola que tenha aprovação automática, mas põem o filho na escola que tem reprovação, mas pro filho dos outros, ele não aceita a reprovação do filho dele; pode reprovar e deve-se reprovar, mas o filho de outro e não o dele, então isto nos traz um pouco de dificuldade.

A fala dos entrevistados deixa entrever que as propostas de educação dos colégios estão articuladas em um duplo movimento. Por um lado, procuram responder a uma prática coerente com os desafios teórico-metodológicos de uma educação atual e inserida na realidade. Por outro, respondem às pressões das raízes culturais de uma sociedade conservadora e elitista. Dessa forma, conseguem bons resultados articulando instrumentos que representam avanços nas práticas pedagógicas com mecanismos que refletem certos traços de uma prática educativa considerada tradicional.

fator econômico tem interferido significativamente para que as escolas particulares correspondam, em seus resultados, com a expectativa de investimento dos pais. Dados estatísticos do Censo Escolar 200 l e fornecidos pela Secretaria Estadual de Educação de Minas Gerais, referentes ao número de matrículas no ensino fundamental, mostram que as escolas particulares no Brasil possuem 9,09\% do total de alunos: em Minas Gerais 6,04\% e na capital, Belo Horizonte, 16,03\%. Ou seja, na atual conjuntura a iniciativa privada 
precisa cuidar muito bem do seu aluno no processo de ensino-aprendizagem, evitar ao máximo grandes atropelos e mostrar que seu projeto de ensino está focalizado no sucesso e não no fracasso. Os pais desejam uma escola exigente, que dê prova, mas que aprove. Em suma, não investem para ver os filhos reprovados.

$\bigcirc$ fato de a proposta dos ciclos de formação amenizar os índices alarmantes de reprovação na escola pública acabou gerando uma situação de contraponto para as escolas particulares defenderem o sistema seriado e, conseqüentemente, a reprovação, quando for o caso. Existe um reconhecimento dos ganhos qualitativos da proposta dos ciclos no processo de avaliação, mas se questionam os resultados obtidos pelos alunos com a implantação desse sistema na Escola Plural. Os entrevistados consideram que ao tentar resolver o problema da reprovação a escola pública não o fez com qualidade. Desse modo, questionam se é justo o aluno receber um ensino de tal natureza quando é de direito tê-lo com qualidade. Explicam que a questão da reprovação passa muito mais pelas metodologias e apoio dado aos alunos e professores do que simplesmente por mudar a organização do tempo escolar.

Muitos dos avanços que ocorreram nas práticas pedagógicas deveramse aos investimentos dos colégios nas estratégias de apoio aos alunos e na capacitação dos professores. A situação é interessante porque aborda um esforço dos colégios na busca de melhorias pedagógicas, a discussão e a reflexão de assuntos que fazem parte dos eixos norteadores da organização dos ciclos de formação, mas revela ao mesmo tempo que, em nenhum momento, a proposta dos ciclos aparece como tema de estudo. Ao que tudo indica, a relação direta que os professores fazem dos ciclos com a promoção automática acabou gerando um esvaziamento qualitativo de sua riqueza pedagógica e, portanto, trata-se de uma expressão que não cabe na cultura da escola particular. Fala-se de muitas possibilidades de ajuda ao aluno, mas nega-se a organização dos ciclos.

\section{Estratégias de apoio ao aluno}

Os colégios sabem de sua responsabilidade pedagógica e de seu compromisso com um ensino de qualidade, mas sabem, também, que trabalham com uma classe social privilegiada, que paga para colocar os filhos numa escola diferenciada, a fim de obter um resultado que corresponda às suas expecta- 
Séries no ensino privado...

tivas. Soma-se a isso a realidade de escola privada na qual se tem o pagante como consumidor consciente. Nessa dimensão de cidadania ninguém quer ser enganado e ninguém compra um serviço ${ }^{2}$ sem garantia de qualidade do produto. No campo da educação, isso significa que nenhuma família investe na escola particular aceitando passivamente a possibilidade de reprovação. Essa situação põe os colégios diante de um duplo desafio quando se deparam com alunos que apresentam dificuldades de aprendizagem: prestar um ensino de qualidade porque esta é a sua razão de ser e porque a família faz um investimento na expectativa do sucesso escolar e profissional. $\bigcirc$ fato é que esse contexto acabou gerando um esforço duplo para que o aluno possa vencer seus estudos. A família e a escola tornam-se parceiras do sucesso.

Esses dados revelam que, nas escolas particulares pesquisadas, os investimentos nas estratégias de apoio têm contribuído significativamente com a redução dos índices de reprovação. Logo, alterando-se as estratégias de ação pedagógica e não necessariamente a organização do tempo escolar, é possível conseguir altos índices de aprovação. Nesse caso, pode-se dizer que as dificuldades relacionadas com o tempo próprio de cada aluno são compensadas com um suporte extra, oferecido pela escola ou pela família.

\section{Possibilidade dos ciclos nos colégios}

No conjunto das entrevistas, percebe-se que, do ponto de vista pessoal, os gestores não apresentam resistências explícitas aos ciclos de formação. Pelo contrário, conceitualmente comungam com os princípios da proposta. Isso não significa, no entanto, que estão mobilizados com a implantação do projeto. $\bigcirc$ fato de acolher, gostar e aprovar a concepção teórica não é motivo suficiente para sua adoção. Existem outras combinações que estão em jogo e precisam ser analisadas. $\bigcirc$ quadro é bastante complexo, existem relatos que se apresentam contraditórios, principalmente quando abordados no campo teórico e prático. Não há uma unidade nas posições. Uns se mostram mais receptivos à proposta dos ciclos, reconhecem os ganhos pedagógicos e se manifestam fa-

2. A lei n. 8.078 (Código de Defesa do Consumidor) estabelece no art. $4^{\circ}$ que a política nacional de relações de consumo está pautada, dentre outros princípios, pela "garantia de produtos e serviços com padrões adequados de qualidade, segurança, durabilidade e desempenho". 
voráveis caso a proposta seja adotada em seus colégios; no entanto, admitem que os riscos acabam ofuscando a motivação. Comentam as resistências da comunidade educativa; professores e famílias mostram-se pouco interessados na viabilização da proposta. Outros se manifestam reticentes em relação aos ganhos que os ciclos podem apresentar. Consideram que é possível incorporar suas vantagens sem alterar a organização do tempo escolar.

Uma situação que demonstra como a concepção dos ciclos repercute nas escolas particulares e, conseqüentemente, no processo ensino-aprendizagem é a forma pela qual alguns colégios manifestam-se preocupados com as rupturas, quebras ou descontinuidades com o processo ensino-aprendizagem. Avaliam a necessidade de uma reorganização das propostas pedagógicas de modo a diminuir os prejuízos que a rotina do sistema seriado impõe à escola. Assim, os colégios apontam que uma das principais medidas adotadas para a superação da fragmentação do ensino seriado foi a reorganização dos conteúdos programáticos, geralmente denominados pelos entrevistados como "organização curricular". Percebe-se que, na dificuldade de reestruturar os tempos escolares a fim de privilegiar os tempos de aprendizagens dos alunos, as escolas, em seu processo de elaboração dos projetos políticos pedagógicos, passaram a falar de uma prática de ensino menos fragmentada com base em uma "organização curricular" mais articulada entre as séries, demonstrando que é possível amenizar as "quebras" dos períodos, segmentos e anos com um tratamento mais adequado aos conteúdos disciplinares, ajustando-os à idade e à capacidade cognitiva de seus alunos.

\section{Implantação dos ciclos nos colégios: dificuldades}

Sabe-se que qualidade em educação é um grande desafio para os diferentes sistemas de ensino. Está garantida como um direito na Constituição Federal de 1988 e na LDB n. 9.394/96. Já não basta o acesso, é preciso, também, oferecer qualidade.

A tônica da qualidade aparece como uma das principais temáticas para se justificar a opção pela continuidade do ensino seriado. Nesse caso, as justificativas apontam para uma relação direta dessa modalidade de organização com um programa que garante a qualidade do ensino. A família quer a continuidade do sistema seriado por razões que ora se justificam no discurso da tradição, da cultura, ora no discurso do mercado que exige qualidade. Já para os 
Séries no ensino privado...

professores o ensino seriado é a alternativa mais viável para se conseguir a disciplina e a qualidade. Por sua vez, os colégios continuam apostando nessa organização porque, segundo eles, é preciso garantir a qualidade do ensino, uma boa imagem da escola e novos alunos matriculados. Enfim, a manutenção da estrutura seriada parece adquirir contornos econômicos, culturais e sociais, distanciando-se dos ciclos de formação que proclamam a escola dos direitos, a escola cidadã, a escola plural.

Para os entrevistados a questão do tempo é apenas uma das variáveis que compõem com a qualidade do processo de ensino-aprenizagem. São muitos os elementos que interferem na construção de um ensino, dentre os quais se destacam: as questões relacionadas à formação dos professores, o currículo escolar, a estrutura da escola, as condições de trabalho, os salários, as relações, a gestão, a proposta pedagógica etc. Mudanças isoladas e sucessivas geram desgastes e trazem insegurança.

Essa parece ser a posição de Cunha que, analisando a expansão do ensino privado durante o regime militar, identifica a deterioração da qualidade da educação pública. Considera que a gestão da educação no Brasil passou a sofrer de um fenômeno, denominado pelo autor "administração ziguezague": trata-se de uma prática segundo a qual, em razão da mudança de prefeitos e governadores, a cada quatro anos a escola fica refém destas articulações políticas. Essa prática, segundo o autor, trouxe conseqüências danosas à escola pública, visto que em educação os resultados dos projetos pedagógicos materializam-se muitos anos após a sua implantação. Com isso, cresceu entre os professores uma desconfiança diante das mudanças que são, normalmente, propostas a cada início de gestão.

Os docentes desenvolvem uma salutar resistência diante dos intentos mudancistas, já que não sabem quanto tempo vão durar (...) Esse hábito de resistir às mudanças inconseqüentes acaba por se fixar e fazer com que não se aceitem até mesmo as políticas educacionais mais sadias e apropriadas. (1998, p. 19)

Para não incorrer no dilema mudancista, percebe-se que uma certa postura mais cautelosa e conservadora foi-se configurando no interior das escolas privadas. A impressão que se tem é que nessa esfera de ensino nem sempre a chegada de uma boa proposta implica necessariamente a sua incorporação na 
mudança da organização corrente. Parece que bons ou novos projetos não são analisados apenas na perspectiva pedagógica, outros fatores precisam ser incorporados, tais como: resistências, impactos, resultados. Evita-se qualquer situação que possa gerar insegurança ou colocar sob suspeita a qualidade do ensino.

São vários os motivos apontados para justificar a não-adoção dos ciclos de formação na escola particular. Os entrevistados afirmam que os colégios sofrem pressão muito grande da família e, nesse caso, pode-se dizer que há uma relação direta da gestão da escola com as demandas da comunidade educativa. A organização escolar estrutura-se também para responder às exigências dos pais.

A interferência da família no espaço escolar acaba gerando um campo de forças no qual se estabelece um jogo ou uma disputa, tendo em vista determinados interesses dos sujeitos envolvidos. Para Bourdieu, quando um ator social age no interior de um campo ${ }^{3}$ específico, está procurando ajustar o seu esquema de pensamento, percepção e ação às exigências objetivas daquele espaço social. E, nesse caso, os campos sociais não podem funcionar a não ser que os agentes que realizam investimentos no seu interior e participam de suas disputas contribuam para a reativação das lutas que nele se desenvolvem. A motivação dos agentes sociais em um determinado campo se dá em função da relação entre o habitus e o campo. Segundo Bourdieu (1989), em decorrência desta relação, o habitus contribui para determinar aquilo que o determina, ou seja, a preservação do campo, dos seus princípios de funcionamento e de organização, assim como a reatualização dos antagonismos nele existentes. Desse modo, pode-se dizer que quando a família age no interior dos colégios particulares fazendo "pressão" para a manutenção da tradição, isso se justifica pela contribuição específica que essa dimensão da vida social fornece para a formação do habitus. Para Bourdieu (1989), a cultura escolar como uma das

3. Explicitando o pensamento de Bourdieu a respeito do conceito de campo, Martins afirma que "um campo se define, entre outras coisas, estabelecendo as disputas e os interesses específicos que estão em jogo, que são irredutíveis às disputas e aos interesses dos outros campos. Estas disputas não são percebidas a não ser por aqueles que foram produzidos para participar de um campo onde se realizam estas disputas. Cada categoria de investimento implica uma certa indiferença em relação a outros interesses, a outros investimentos, específicos a um outro campo. Para que um campo funcione é preciso que haja lutas, ou seja, indivíduos que estejam motivados a jogar o jogo, dotados de habitus implicando o reconhecimento das leis imanentes dos jogos" (Bordieu, apud Martins, 1990, p.67). 
Séries no ensino privado...

agências formadoras do habitus propicia aos indivíduos a ela submetidos um corpo comum de categorias de pensamento, um código comum de percepção e de apreciação que tende a funcionar como forma de classificação dos homens e das coisas. Isso ocorre, visto que o saber escolar separa os indivíduos que estiveram expostos à sua ação daqueles que, por diversas razões, foram excluídos de sua apropriação. Assim, para esse autor, a escola proporciona aos agentes que estão sob seu raio de ação muito mais que esquemas de pensamentos, mas um sistema complexo de disposições (habitus) capaz de funcionar como estruturas classificatórias, possíveis de serem aplicadas nas mais diversas realidades.

Uma outra dimensão dos estudos de Bourdieu que pode ser explorada quando se trata da presença da família na dinâmica da escola particular referese ao capital cultural. A escola é vista como um espaço capaz de oferecer chances razoáveis de satisfazer a todas as suas expectativas de êxito social e prestígio cultural. Para Bourdieu,

... as crianças das classes médias devem à sua família não só os encorajamentos e exortações ao esforço escolar, mas também um ethos de ascensão social e de aspiração ao êxito na escola e pela escola, que lhes permite compensar a privação cultural com a aspiração fervorosa à aquisição de cultura. (apud Nogueira, Catani, 1999, p.48)

Enfim, para o autor, a combinação do capital cultural com o éthos social acaba concorrendo para definir as condutas escolares e as atitudes da família diante da escola, constituindo um princípio de eliminação diferencial das crianças das diversas classes sociais.

Ainda, segundo os gestores das escolas particulares, a Escola Plural é um exemplo que interfere negativamente nas discussões sobre os ciclos de formação. Sempre que o tema é tratado, acabam prevalecendo nas discussões as dimensões negativas que a proposta trouxe. Existe uma resistência da comunidade e dos professores em razão do efeito da Escola Plural.

Por fim, a estrutura do sistema educacional brasileiro também foi apontada como um problema que dificulta a organização em ciclos. A temática central é o vestibular. Os programas exigidos inviabilizam uma organização mais qualitativa. Os pais pagam e querem ver seus filhos passando nas melhores universidades e, de preferência, públicas. 


\section{Argumentos para a defesa do sistema seriado}

Existem práticas ou situações que fazem parte do nosso cotidiano e, com razão de ser, muitas vezes não nos preocupamos com elas. Sempre foi assim, desde antigamente, é costume, é tradição, nunca ninguém pensou em mudar. É assim porque é assim.

Por incrível que pareça, essa situação apresenta-se como uma das respostas para a organização do ensino seriado na rede privada de Belo Horizonte. É claro que este "é assim porque é assim" pode num primeiro momento ter uma conotação simplista ou ingênua, mas numa investigação mais aprofundada revela-se tratar de uma expressão carregada de sentido, pela qual existe muita coisa sendo dita. Na sua raiz, reportar ao passado ou à tradição seriada significa resgatar uma identidade racional e liberal. Uma organização criada no século XIX e que se ajusta às demandas do mercado de trabalho.

No conjunto, a pesquisa mostra que os gestores apresentam várias posições para justificar a adoção da organização seriada em seus colégios. $\bigcirc$ que se percebe é que existe todo um esforço para defender a organização seriada, sem, contudo, negar dimensões qualitativas dos ciclos de formação. $\bigcirc$ fato é que não existe nenhum tipo de questionamento sobre a concepção dos ciclos, mesmo porque se trata de fundamentos constitutivos do processo de formação humana. Então, verifica-se que, nos colégios, costura-se uma articulação do tempo escolar mesclando a temporalidade seriada com eixos teórico-metodológicos dos ciclos. Os depoimentos revelam que existe um movimento de incorporação das práticas dos ciclos e, ao mesmo tempo, a conservação da estrutura formal da temporalidade seriada. Verifica-se, que foi exatamente na dimensão do tempo que os colégios menos avançaram. Os gestores limitaramse a dizer que, nos últimos anos, passaram a adotar trimestre em vez do bimestre, para evitar assim uma ruptura com a tradição.

No processo de incorporação das dimensões dos ciclos, a organização dos conteúdos curriculares é citada como um exemplo. Esses conteúdos passaram por uma reorganização seguindo uma lógica seqüencial, espiralada e foram ajustados à idade dos alunos. Os gestores apontam que a construção desse caminho foi devida à orientação dos consultores contratados para assessorar a elaboração do projeto pedagógico

Esse movimento de reorganização dos conteúdos escolares apresentase como uma preocupação da maioria dos entrevistados, principalmente no 
Séries no ensino privado...

ensino fundamental, em que o stress do vestibular não é tão grande. Pode-se dizer que, nessa etapa de ensino, a preocupação está centrada no processo de formação humana, e isto tem exigido dos colégios uma revisão da concepção "etapista", acumulativa e transmissiva dos saberes, característica do ensino seriado. Novos critérios para a seleção e seqüência dos conteúdos, tais como adequação relativa ao desenvolvimento dos alunos, eixos norteadores e vivências foram ou estão sendo incorporados pelos professores. Assim, esse movimento desencadeado nas escolas particulares, na construção do projeto político pedagógico, é percebido como alternativa que se aproxima da concepção dos ciclos. A proposta curricular de organização dos conteúdos da Escola Plural rompe com o modelo pautado na precedência e na quantidade. Define "o processo, a dinâmica, o movimento de ir e vir, e os avanços na retomada como seu eixo norteador" (Belo Horizonte, s.d., p. I4).

Analisando de forma cuidadosa um conjunto de palavras utilizadas no decorrer das entrevistas foi possível detectar que elas forneciam elementos para uma reflexão mais cuidadosa sobre os motivos da sustentação da organização seriada, tais como: monitorar, definir, controlar, exigir, cobrar, preparar, repetir, treinar, competir, conseguir, passar, desafiar, provar, superar, pressionar, fracasso, comportamento, separar, resultado, habilidade, aprendizagem, mercado, sucesso, meta, objetivo, tempo.

Apoiando-se em Betto (2003), para quem as palavras possuem identidade, pode-se afirmar, nesse caso, que elas falam por si mesmas, aproximam-se de uma realidade que extrapola os muros da escola, ou melhor, falam de uma realidade a ser vivida pelo aluno fora da escola. Falam das relações de trabalho, do mercado, da competição, da vida dura que o jovem enfrentará no cotidiano para sua sobrevivência. Os entrevistados explicam que a família deseja uma escola conectada com o mercado profissional valorizado. Não querem uma escola que não corresponda às expectativas dos seus investimentos. Desejam que seus filhos aprendam, construam conhecimentos, vivenciem experiências formativas, mas esperam também uma ação pedagógica que capacite os alunos para sua inserção competitiva no mercado. Por isso, essa escola precisa monitorar, definir, controlar, exigir, cobrar, treinar, desafiar, provar, pressionar. Deseja-se uma escola que proporcione o pleno desenvolvimento do educando, mas também a sua preparação qualitativa para o mercado de trabalho.

Ao que parece, os colégios têm buscado investir num movimento que tenta combinar o pleno desenvolvimento do educando e a sua preparação para 
o trabalho. Um movimento em consonância com a definição do art. 205 da Constituição Federal que estabelece que a educação visa ao "pleno desenvolvimento da pessoa, seu preparo para o exercício da cidadania e sua qualificação para o trabalho". Nesse caso, pode-se dizer que esse movimento dos colégios assume contornos de um arranjo no qual as escolas adotaram uma medida denominada "solução de compromisso", ou seja, incorporaram novas concepções de educação mais coerentes com o "pleno desenvolvimento do educando," sem, contudo, romper com interesses específicos da comunidade escolar ou, mais especificamente, das famílias.

Além da tradição e do mercado, é possível identificar nos textos das entrevistas outras razões pelas quais os colégios continuam sustentando a organização seriada. Certamente, existem algumas posições dos gestores que podem ser questionadas: se pedagogicamente estão corretas ou não, que concepção de homem ou de sociedade apresentam ou defendem; no entanto, cabe neste momento apenas reproduzir o que está sendo dito, dar visibilidade às razões pelas quais os colégios continuam com a organização seriada. Nessa categoria de análise é possível identificar, ainda, os seguintes motivos:

a. o ensino seriado permite um monitoramento mais contínuo dos alunos, visto que passam por provas contínuas de avaliação de desempenho; por sua vez, esse monitoramento permite uma intervenção mais pontual para atender os alunos que estão com alguma dificuldade e, nessa condição, respondem de uma forma mais rápida mediante as estratégias de apoio paralelo oferecidas pelos colégios;

b. a escola seriada apresenta-se para o aluno com uma estrutura mais exigente. Impõe-se de uma forma mais desafiadora, isto é, o aluno precisa ajustar-se a uma rotina marcada pela cobrança contínua de provas, exercícios, vestibulares, práticas que darão a ele a condição de perceber seu progresso e dizer: eu passei, eu não passei, eu consegui;

c. a organização seriada tem uma relação direta com a nossa vida. Tudo tem começo meio e fim. O tempo do cotidiano é fragmentado e vivemos esta realidade continuamente. Existem ritos de passagem que culturalmente reforçam o ciclo anual. Vivemos uma cultura cronológica do ano e a organização seriada ajusta-se a essa demanda. Possibilita ao aluno no final do ano avaliar se deu conta ou não de cumprir sua meta e seus objetivos; 
Séries no ensino privado...

d. a natureza humana precisa de condições exógenas que determinem uma pressão sobre o comportamento dos alunos de tal forma que possam vencer uma condição natural de conforto e tendência à acomodação. Só motivação não é suficiente para despertar o aluno para o estudo, ele precisa sentir-se pressionado e desafiado;

e. vivemos em uma sociedade em que tudo está marcado pela competição, o trabalho, o esporte, a política. $\bigcirc$ alunado incorpora essa disposição e, nesse sentido, a organização seriada valoriza o esforço individual permitindo a experiência do sucesso e da conquista. A possibilidade da retenção permite à escola preparar melhor aquele aluno que não tem as habilidades, o conhecimento ou a maturidade para continuar. $\bigcirc$ atleta que não está bem condicionado precisa de mais treinamento para chegar ao nível dos outros e às vezes até superálos. A organização seriada permite um enquadramento do desempenho dos alunos e a sua condição para avançar nas séries seguintes.

f. a idéia de que as pessoas ocupam posições diferentes na sociedade e que, por isso, a educação não pode ser a mesma para todos ganha destaque quando a família não aceita a escola de aprovação automática. A defesa do ensino seriado é sustentada, entre outros motivos, pela possibilidade da reprovação, o que reflete uma cultura escolar que ainda acredita que a qualidade do ensino compõe-se com a seletividade dos alunos. Aliás, quando a família manifesta-se pela continuidade do ensino seriado, certamente está demarcando um modelo de organização escolar que melhor se configura com sua identidade de classe social.

\section{CONCLUSÃO}

Os colégios particulares pesquisados na cidade de Belo Horizonte, embora tenham feito a opção pela continuidade da organização seriada, revelam que seus índices de reprovação não correspondem à realidade excludente verificada ao longo do século $X X$, não correspondem a uma prática comum nos estabelecimentos de ensino atribuída a essa lógica de organização.

No entanto, verifica-se mediante a pesquisa que o movimento pedagógico que se desenvolveu ao longo da segunda metade do século $X X$, na tentativa de romper com a lógica seriada e repensar outras possibilidades de orga- 
nização escolar, trouxe inúmeros benefícios. Práticas pedagógicas foram ressignificadas, concepções de educação reveladas, políticas flexibilizadas. Não há como negar que a concepção dos ciclos introduziu um novo olhar, um novo jeito de pensar e fazer educação. Foram muitas as mudanças qualitativas introduzidas na prática pedagógica, tendo em vista a crítica à evasão e à repetência e o valor representado pela escola para seus estudantes.

A pesquisa mostra que, embora as escolas particulares abordadas não tenham adotado essa "nova" modalidade de organização, as intenções pedagógicas dessa modalidade têm sido incorporadas. Dimensões da proposta dos ciclos de formação foram de alguma forma ressignificadas para se enquadrarem na estrutura seriada: os tempos foram ampliados, passaram de bimestre para trimestre; a interdisciplinaridade, a pedagogia de projetos, as práticas avaliativas processuais, diversificadas e formativas, a contextualização e a revisão qualitativa dos conteúdos, a escola como um espaço de vivência cultural, tudo tem sido trabaIhado de alguma forma nos colégios pesquisados. As temáticas apresentadas como eixos norteadores do Programa da Escola Plural estão presentes nas discussões e práticas pedagógicas destes colégios sem que sejam feitas referências à expressão "ciclo". Percebe-se, então, que existe uma negativa à expressão nominativa, mas, ao mesmo tempo, as escolas apropriam-se de atributos do regime de ciclos e mantêm a estrutura organizacional e funcional da seriação.

A pesquisa também revela que existem dois movimentos distintos nos depoimentos. Quando os gestores falam de práticas implementadas em seus colégios, que correspondem à proposta dos ciclos de formação, evidenciam uma intenção pedagógica que coloca o aluno como centro do processo ensino-aprendizagem. Em contrapartida, quando se reportam à tradição, ao costume ou à família para justificar a organização seriada, manifestam a necessidade de os colégios estarem sintonizados com as demandas do mercado. Trata-se de uma combinação saudável e legalmente constituída. A lei define como finalidade da escola possibilitar "o pleno desenvolvimento do educando e sua qualificação para o trabalho". Nesse sentido, as falas reforçam que o ensino seriado favorece uma ação pedagógica que exige do aluno atitudes de disciplina, seriedade, cobrança, resultado, controle, meta, objetivo, sucesso. Indicam que essa modalidade de organização imprime um ritmo dinâmico ao tempo escolar que ajuda em algumas dimensões formativas. Trata-se de uma dimensão inerente ao cotidiano e à vida que, incorporada ao projeto pedagógico, insere o processo de ensino e aprendizagem no mundo que extrapola os muros da 
Séries no ensino privado...

escola. Nesse contexto, parece que o grande desafio dessas práticas está na atitude equilibrada do professor em suas intervenções. Não se pode perder de vista que o aluno é o sujeito da aprendizagem e que ela se desenvolve num processo muito complexo. $\bigcirc$ problema dessas intervenções pedagógicas ocorre quando elas se deslocam para uma intervenção centrada, arbitrariamente, no poder do professor, quando elas caracterizam juízos de valor e passam a definir a vida escolar do aluno.

Uma outra situação revelada pela pesquisa é que os resultados finais dos colégios particulares não confirmam uma relação direta do ensino seriado com a reprovação. Seus índices de aprovação caracterizam-nos como escolas de sucesso. Assim, esses dados rompem com uma visão determinista em relação a essa organização de ensino. Neste momento, entendo ser necessário uma ruptura com o dualismo que tem permeado os estudos sobre o ensino seriado e os ciclos de formação. Quando em nosso cotidiano questionamos os depoimentos que se marcam pela polarização, ou seja, posições que levam aos extremos, tais como: "todo político é corrupto," "a polícia não presta," "funcionário público é folgado," parece-me que o mesmo ocorre com ciclo e seriação. Quando as pessoas estabelecem uma relação direta do ciclo com promoção automática tendem para um juízo valorativo, estabelecendo uma relação de correspondência como um dispositivo que permite a aprovação automática e, ao mesmo tempo, ensino de qualidade suspeita. $\bigcirc$ mesmo movimento de polarização também parece existir sobre o ensino seriado. A literatura de modo geral trata esta concepção como uma organização escolar que seleciona, classifica e exclui. $\bigcirc$ fato é que os altos índices de aprovação, revelados na pesquisa, dentro da lógica seriada, indicam que essa modalidade de organização não tem em si a força da exclusão e a recíproca pode ser dita em relação aos ciclos de formação. Eles também não têm em si a força de um projeto que garanta o pleno desenvolvimento humano. A pesquisa aponta que essa relação está diretamente determinada pelo movimento que se estabelece dentro da escola. A escola de sucesso define-se na cumplicidade dos educadores com a construção de um projeto pedagógico voltado para a formação dos alunos. Outras variáveis são muito importantes: condições de trabalho, estrutura física, salários, formação em serviço etc. É preciso entender que a qualidade de um projeto de educação se assenta em um conjunto de variáveis. A estrutura da organização do tempo escolar não pode ser absolutizada como a responsável pelo sucesso ou fracasso dos alunos. 
Nesse contexto, faz-se necessário uma segunda ruptura. Acabar com uma visão um tanto maniqueísta sobre ciclo e seriação. Se a lei aponta ambas as organizações como possibilidades alternativas, tornam-se contraditórios os discursos que tentam delimitar qual é a melhor ou a pior delas. Elas existem e obedecem a lógicas diferentes de organização do tempo escolar. Cabe às instituições de ensino definir qual viés é mais adequado ao projeto de educação que pretende desenvolver. Nesse caso, avaliar ou julgar projetos de educação considerando apenas a lógica da organização do tempo escolar parece pouco coerente.

Por fim, o movimento de continuidade do ensino seriado nos colégios particulares indica que existe uma lacuna teórica sobre a "real" importância dos pressupostos dessa organização para a inserção dos indivíduos na vida e no mercado de trabalho. Ora, se de fato essas dimensões são relevantes, fica difícil pensar a escola sem elas. Conseqüentemente, as escolas que adotam os ciclos teriam que rediscutir algumas coordenadas pedagógicas. Não obstante, se for uma questão cultural ou uma questão classista, pode ser que com o tempo, o próprio avanço da proposta dos ciclos contribua para a desmistificação da concepção seriada. De qualquer forma, a temática dessa pesquisa traz para o centro das discussões a necessidade de se pensar a educação no país de uma perspectiva mais profunda. Em outras palavras, o que de fato faz a diferença e, portanto, determina a qualidade do ensino não é ciclo ou seriação, mas um projeto político pedagógico bem definido e alicerçado por políticas públicas consistentes, bem como a melhor distribuição da renda.

\section{REFERÊNCIAS BIBLIOGRÁFICAS}

ARROYO, M. G. Reinventar e formar o profissional da educação básica. In: BICUDO, M. A. V.; SILVA Jr., C. (orgs.) Formação do educador, I. São Paulo: Unesp, 1996. p.49-50.

ASSMAN, H. Metáforas novas para reencantar a educação: epistemologia e didática. 2.ed. Piracicaba: Unimep, 1998.

BARRETTO, E. S. S.; MITRULIS, E. Trajetória e desafios dos ciclos escolares no país. Estudos Avançados, São Paulo, v. I5, n. 42, p. I-39, 2001.

BELO HORIZONTE. Prefeitura Municipal. Cadernos escola plural, 2: proposta curricular da escola plural; referências norteadoras, s.d. 
Séries no ensino privado...

BETTO, F. Gosto de uva : escritos selecionados. Rio de janeiro: Garamond, 2003.

BOURDIEU, P. O Poder simbólico. Lisboa: Difel, 1989.

BRASIL. Constituição (1988). Constituição da República Federativa do Brasil. Brasília: Senado, 1988.

BRASIL. Lei n. 9.394 de dezembro de 1996. Lei de diretrizes de bases da educação nacional. Brasília: Senado, 1996.

CUNHA, L. A. Educação pública: os limites do estatal e do privado. In: OLIVEIRA, R. P. de (org.) Política educacional impasses e alternativas. 2.ed. São Paulo: Cortez, 1998. p. 18.

CURY, C. R. J. et al. Medo à liberdade e compromisso democrático: LDB e Plano Nacional da Educação. São Paulo: Editora do Brasil, 1997.

MARTINS, C. B. A Pluralidade dos mundos e das condutas sociais: a contribuição de Bourdieu para a sociologia da educação. Em Aberto, Brasília, v.9, n.46, p.67, abr./jun. 1990.

NOGUEIRA, M. A.; CATANI, A. (orgs.) Escritos de educação: Pierre Bourdieu. Petrópolis: Vozes, 1999.

PATTO, M. H. S. A Produção do fracasso escolar : histórias de submissão e rebeldia. São Paulo: T. A. Queiroz, 1993.

SAVIANI, D. Escola e democracia: teorias da educação, curvatura da vara, onze teses sobre a educação política. 33.ed. Campinas: Autores Associados, 2000.

Recebido em: novembro 2004

Aprovado para publicação em: março 2005 